\title{
VOTO OBRIGATÓRIO E EQÜIDADE um estudo de caso
}

\author{
Luzia Helena Herrmann de Oliveira \\ Professora do Departamento de Ciências Sociais da Universidade Estadual de Londrina
}

$\mathrm{O}$ voto obrigatório foi implantado no Brasil com o Código Eleitoral de 1932 e transformado em norma constitucional a partir de 1934. Regulamentado em um período de transformações institucionais que objetivavam dar credibilidade ao processo eleitoral, foi justificado como uma necessidade para garantir a presença dos eleitores nas eleições. Como afirmava Assis Brasil (1931:86), "é conveniente ao interesse social que todos os cidadãos capazes se inscrevam eleitores e votem", completando em seguida que "não são inócuas nem desprezíveis certas providências legais, tendentes a fazer com que a totalidade dos cidadãos se aliste e vote".

Embora muitas vezes apresentada como uma norma pouco democrática, a obrigatoriedade do voto é uma medida institucional adotada em muitas democracias estáveis. E os motivos para essa adoção costumam obedecer a critérios políticos democratizadores, tais como conseguir a participação de grupos religiosos, minorias políticas ou, simplesmente, garantir a presença da maioria nas eleições (Nohlen, 1981).

No Brasil, a razão principal da adoção do voto obrigatório, em 1932, foi o temor de que uma participação diminuta pudesse tirar a legitimidade do processo. Realmente, em razão dos impedimentos legais (sobretudo a exclusão dos analfabetos) e das condições históricas de um país eminentemente rural, o eleitorado da época restringia-se a cerca de $10 \%$ da população adulta, o que significava um número muito reduzido (Soares, 1973). Contudo, com as transformações da sociedade brasileira e a concessão dos direitos políticos aos maiores de 16 anos e aos analfabetos, esse percentual cresceu expressivamen- te. Para as eleições de 1998, foram inscritos 106.076.088 eleitores de um total de 157.070.163 habitantes, ou seja, $67 \%$ da população brasileira (TSE, 1998a; IBGE, 1998a).

Hoje, com a plena instauração da sociedade urbanoindustrial e a redemocratização iniciada nos anos 80 , o tema da obrigatoriedade retorna, com tendência à eliminação da compulsoriedade. ${ }^{1}$ Paralelamente, estudos mostram que mudanças na legislação exercem um impacto sobre o comportamento eleitoral da população. Na Venezuela, análises realizadas anteriormente à reforma de 1993 indicavam a possibilidade de uma significativa queda na participação política, o que foi confirmado pelos fatos. ${ }^{2}$ Na Holanda, Irwin (1974) também observou mudanças nas atitudes dos eleitores após a implantação do voto facultativo em 1971. Trata-se, portanto, de uma preocupação pertinente: qual seria o impacto da implantação do voto facultativo no Brasil?

Esse é o tema abordado neste artigo. Com base na literatura política comparada e nos dados coletados em uma pesquisa de opinião realizada no Município de Londrina (PR), entre abril e maio de 1997, pretende-se analisar as possíveis implicações da regulamentação do voto facultativo no Brasil, buscando compreender quem deixaria de votar e em que medida isto afetaria o processo democrático brasileiro. $^{3}$

\section{AS DEMOCRACIAS REAIS}

Ao contrário do ideal clássico democrático, que prega o desenvolvimento da liberdade, da participação e do envolvimento sempre mais profundo dos cidadãos com 
as causas públicas, pesquisas sobre o funcionamento real das democracias ocidentais costumam provocar um grande sentimento de frustração. Como os cientistas políticos vêm há décadas procurando demonstrar, a idéia de uma opinião pública autônoma, composta por indivíduos independentes e dotados de grande discernimento político, não se verifica nem mesmo nas maiores e mais estáveis democracias ocidentais.

Pelo contrário, importantes pesquisas empíricas, realizadas a partir da década de 40, foram desvendando hábitos e atitudes de um homem médio pouco participativo e alheio a movimentos e organizações políticas. A intensidade da participação dos cidadãos pode variar substancialmente de uma nação para outra, mas não existe caso conhecido em que a maioria da população de um determinado país se encontre ativamente engajada em organizações políticas.

Observa-se que as oportunidades oferecidas pela sociedade diferem profundamente e essa base social interfere, produzindo graus de motivação e interesse bastante diversos. Não existem meios conhecidos de se estabelecer uma eqüidade entre o grau de participação e a influência que os indivíduos possam exercer sobre os governos. Formas diferenciadas de organização e pressão políticas resultam, igualmente, em capacidades de influência muito diversas. Para muitos autores, ${ }^{4}$ participar politicamente é o momento final de um longo processo, que se encontra relacionado à capacidade de ler, falar, pensar e agir. Visto sob este prisma, o preceito constitucional de que cada indivíduo vale um voto transforma o ato de votar no único mecanismo de expressão política que mantém a eqüidade entre os cidadãos.

Com base na constatação de que os graus de interesse e a motivação política variam muito, criou-se dentro da ciência política intenso debate sobre a influência dessa maioria, que é passiva, nos destinos da democracia.

Uma primeira postura, desenvolvida por Robert Dahl, foi questionar até que ponto a frustração de minorias ativas, provocada pela vitória da maioria passiva, reflete na estabilidade democrática. Segundo Dahl, é problemático considerar que uma maioria pouco motivada possa eleger um candidato, em detrimento de uma minoria bastante participativa e interessada, mas que não consegue o número suficiente de votos para vencer. Segundo o autor, 'transformando 'o mais preferido' no equivalente ao 'preferido pela maioria' ladeamos deliberadamente um problema crucial: o que acontecerá se a minoria preferir sua alternativa muito mais ardentemente do que a maio- ria prefere a alternativa contrária? Fará ainda sentido o princípio da maioria? Coloca-se aqui o problema da intensidade" (Dahl, 1989:93).

Analisando esta questão, Giovanni Sartori (1994) reafirma sua crença na institucionalidade liberal, enfatizando que o papel desses grandes grupos não-militantes é exatamente imprimir um caráter de comedimento e equilíbrio ao processo político. Para ele, a centralidade democrática seria mais facilmente conseguida com essa variedade de motivações, uma vez que o indivíduo politicamente engajado costuma ser mais apaixonado que reflexivo, e às vezes extremista. Na visão de Sartori, a democracia depende da construção de um "consenso pluralista" e a maneira mais segura de obtê-lo é desenvolvendo a qualidade do cidadão médio formador da opinião pública.

Um terceiro elemento nesta discussão é a observação empírica de que o grau de motivação e interesse político relaciona-se à estrutura econômica da sociedade. É sabido que fatores culturais e socioeconômicos interferem no grau de interesse dos cidadãos pela política. Conforme a literatura, as taxas de abstencionismo crescem no momento em que o corpo eleitoral é ampliado, com a concessão de direitos às mulheres ou às minorias; por exemplo, são as mulheres, os indivíduos com menor grau de escolaridade, os muito jovens e muito idosos e os moradores nas regiões rurais que costumam participar menos. O nível de renda é outro fator ponderável: entre os mais pobres encontram-se os indivíduos menos informados, menos politizados e, conseqüentemente, menos motivados a participar do processo eleitoral (Lipset, 1967; Wolfinger e Rosenstone,1980; Verba, Nie e Kim, 1987).

Evidentemente, a questão da motivação e do interesse encontra-se diretamente relacionada à questão da obrigatoriedade ou facultatividade do voto. Estas implicações vêm sendo estudadas em âmbito global, mas têm merecido poucas análises especificamente brasileiras. Isso não impede, entretanto, o desenvolvimento de um generalizado movimento em direção do voto facultativo no Brasil. Por um lado, os adeptos do voto facultativo acreditam que votar é um direito, não um dever, e a facultatividade faria com que apenas os verdadeiramente interessados participassem, melhorando a qualidade da democracia. Nessa corrente, encontram-se aqueles que relacionam a falta de interesse político com o desapego aos valores democráticos. Nesse sentido, manter os desmotivados afastados seria positivo para a democracia. Por outro lado, as pessoas favoráveis ao voto obrigatório en- 
fatizam que votar é um dever cívico que diz respeito a todos, inclusive aos mais apáticos. Portanto, nesse caso, o fundamental é garantir a presença do maior número de pessoas. Embora, por vezes, este debate assente-se sobre princípios doutrinários pouco permeáveis às evidências empíricas, os dados observados podem ser valiosos para o enriquecimento desta discussão.

\section{PARTICIPAÇÃO: FATORES INDIVIDUAIS E INSTITUCIONAIS}

Existe certo consenso na literatura política de que o voto compulsório faz crescer o comparecimento às eleições; entretanto, isto pode significar muito pouco em termos de participação efetiva. Mesmo sob o regime do voto obrigatório, a diferença no percentual de participação pode variar significativamente, caso seja considerada a população apta para votar ou a população de eleitores registrados. José Molina Vega (1989), estudando um período de três décadas, fez essa comparação em eleições nacionais da Venezuela e chegou à conclusão de que esse percentual sofre uma queda de $90,1 \%$ para $82,7 \%$ naquele país.

No Brasil, o comparecimento dos eleitores com registro gira em torno de $85 \%$, o que pode ser considerado um índice alto de participação. ${ }^{5}$ Contudo, um percentual mais exato poderia ser obtido se fosse feita a relação entre os que efetivamente votaram e os indivíduos em idade de votar, como sugerido anteriormente. Outra maneira ainda mais elaborada para chegar-se ao percentual de participação seria obter o índice de "alienação eleitoral", entendido como a soma das abstenções com os votos nulos e em branco (Santos, 1987). Utilizando-se este tipo mais acurado de análise, percebe-se que a taxa de alienação eleitoral é bem mais alta e irregular, afetando de maneira diferenciada os diversos tipos de eleição.

Resultados eleitorais mostram que a participação é maior para a escolha dos cargos executivos e menor quando as eleições são para os cargos legislativos. Citam-se como exemplo, as eleições de 1994 no Município de Londrina (PR): $69 \%$ da população em idade de votar indicou um candidato para presidente da República; para governador, esse índice caiu para 65\%; senador, 53\%; deputado estadual, $52 \%$ e deputado federal, $44 \% .{ }^{6}$ Uma explicação possível para o fato é que o sistema presidencialista vigente no Brasil tende a valorizar a figura dos representantes do poder Executivo, oferecendo um caráter mais competitivo a esse tipo de eleição. Sendo assim, mesmo os eleitores pouco motivados teriam maior facilidade em participar. Além disso, observa-se que também em outros países algumas eleições são mais valorizadas que outras, podendo-se afirmar que esse não é um problema exclusivamente brasileiro.

Entretanto, tais índices de alienação ocorrem sob o regime do voto obrigatório que, em tese, deveria levar a uma ampla participação. Somado a isso, observa-se que os percentuais de alienação no Brasil são bastante altos, atingindo, em alguns casos, mais de $50 \%$ dos eleitores. Assim, torna-se relevante conhecer mais a fundo as formas desse desinteresse e a quem ele atinge. Com este intuito, a pesquisa em Londrina solicitou aos entrevistados que respondessem para quem foi seu voto nas eleições de 1994, separando as respostas entre os eleitores que votariam com certeza e os que não votariam. Os resultados confirmam que há claras diferenças entre essas duas posturas, embora seja visível o grau de desinteresse pelas eleições legislativas também entre os que votariam com certeza. ${ }^{7}$

Observa-se-se pela Tabela 1, que os índices de alienação crescem significativamente entre os que não votariam: 30,9\% nas eleições para presidente (contra 12,9\% dos que votariam com certeza); 36,8\% para governador (contra 16,1\%); 43,3\% para senador (contra 21,8\%); $43,9 \%$ para deputado federal (contra $21,9 \%$ ); e $45,1 \%$ para deputado estadual (contra 22,6\%). O grau de lembrança entre os dois segmentos é igualmente diverso: $68,9 \%$ dos que votariam com certeza souberam responder para quem foi seu voto para presidente da República, contra apenas $41,3 \%$ dos que não votariam. Entre os que não votariam, somente $9,1 \%$ conseguiram dizer quem foi seu candidato para deputado estadual, contra $20,7 \%$ dos que votariam com certeza.

Entretanto, é preciso reconhecer que, mesmo entre os que votariam com certeza, os percentuais de "não se lembra" são altos, atingindo em torno de $50 \%$ para os cargos legislativos. Há diferenças claramente definidas entre os que pretendem e os que não pretendem participar, mas a qualidade da participação dos que votariam com certeza e, portanto, daqueles que parecem mais motivados pela política também deixa muito a desejar.

Verba, Nie e Kim (1987) afirmam que dois elementos são determinantes para explicar o nível de participação de cada um na política: de um lado, as capacidades individuais, estreitamente relacionadas com as condições sociais e econômicas; de outro, as ações institucionais, que atuam como contrapeso, favorecendo ou prejudicando os segmentos sociais que não possuem condições individuais de pressionar e influenciar os governos. No caso brasilei- 
TABELA 1

Eleitores que Votariam e que não Votariam em Situação de Voto Facultativo, por Cargo Eletivo, segundo Grau de Lembrança do Voto nas Eleições de 1994

Londrina - 1997

\begin{tabular}{|c|c|c|c|c|c|c|c|c|c|c|}
\hline \multirow[b]{2}{*}{ Grau de Lembrança } & \multicolumn{2}{|c|}{ Presidente } & \multicolumn{2}{|c|}{ Governador } & \multicolumn{2}{|c|}{ Senador } & \multicolumn{2}{|c|}{ Dep. Federal } & \multicolumn{2}{|c|}{ Dep. Estadual } \\
\hline & Votariam & $\begin{array}{c}\text { Não } \\
\text { Votariam }\end{array}$ & Votariam & $\begin{array}{c}\text { Não } \\
\text { Votariam }\end{array}$ & Votariam & $\begin{array}{c}\text { Não } \\
\text { Votariam }\end{array}$ & Votariam & $\begin{array}{c}\text { Não } \\
\text { Votariam }\end{array}$ & Votariam & $\begin{array}{c}\text { Não } \\
\text { Votariam }\end{array}$ \\
\hline Não Lembra (\%) & 17,3 & 27,9 & 23,1 & 34,4 & 49,9 & 48,2 & 52,3 & 47,6 & 56,7 & 45,7 \\
\hline Abst./Nulo/Branco (\%) & 12,9 & 30,9 & 16,1 & 36,8 & 21,8 & 43,3 & 21,9 & 43,9 & 22,6 & 45,1 \\
\hline Soube Responder (\%) & 69,8 & 41,3 & 60,9 & 28,8 & 28,4 & 8,5 & 25,8 & 8,5 & 20,7 & 9,1 \\
\hline Números Absolutos (1) & 364 & 163 & 360 & 163 & 363 & 164 & 365 & 164 & 363 & 164 \\
\hline
\end{tabular}

Fonte: Pesquisa sobre Obrigatoriedade de Voto.

(1) 368 entrevistados responderam que votariam com certeza e 167 afirmaram que não votariam. Nota: Exclui os entrevistados que não responderam.

ro, há uma soma de fatores negativos que atuam no sentido de manter a desigualdade política. De acordo com os dados de Londrina (Tabela 2), existe uma correlação positiva entre interesse em votar e nível de renda ou educação. Entre os que não votariam, há diferenças de 17,3\% entre o primeiro e o último nível de renda e $26,0 \%$ entre os dois extremos de escolarização.

Conforme observado anteriormente, clássicas pesquisas de opinião demonstraram existir diferenças de comportamento político relacionadas à estratificação econômica e à escolaridade. Segundo Lijphart (1997), nos países em que a participação eleitoral é maior, essas diferenças tendem a ser menores, mas também ocorrem. Nos países com níveis tradicionalmente baixos de participação, a influência da renda e a da escolaridade tendem a ser mais altas. Esse fator é agravado nos países regidos pelo voto facultativo. No Canadá, por exemplo, onde o voto é facultativo, pesquisas constataram que as diferenças percentuais entre a participação dos mais e dos menos esco- larizados chega a cerca de $10 \%$. Comparativamente, percebe-se que a diferença percentual entre os mais e os menos escolarizados apresentada na pesquisa de Londrina, para a hipótese de o voto se tomar facultativo, é de $26 \%$. Isso demonstra a dramaticidade do caso brasileiro, em que o quadro de desigualdade social contribuiria para agravar o isolamento e alienação dos cidadãos. ${ }^{8}$

A educação, em primeiro lugar, e o nível de renda, em segundo lugar, atuam como desestimuladores da participação, uma vez que isolam o indivíduo da vida pública. Isto pode ser observado na Tabela 3, que procura compreender o grau de interesse dos cidadãos pela política segundo o nível de renda e escolaridade. Com o intuito de avaliar em que medida os entrevistados são envolvidos pelo debate político, lhes foi perguntado sobre a frequiência com que estas questões são discutidas dentro do círculo doméstico. A resposta demonstra que, nitidamente, o interesse cresce à medida que se eleva o nível de renda e escolaridade. ${ }^{9}$

TABELA 2

Eleitores, por Renda Familiar e Nível de Escolaridade, segundo Predisposição de Votar em Situação de Voto Facultativo Londrina - 1997

\begin{tabular}{|c|c|c|c|c|c|c|c|c|c|}
\hline \multirow[b]{2}{*}{ Predisposição de Votar } & \multicolumn{5}{|c|}{ Renda Familiar } & \multicolumn{4}{|c|}{ Nível de Escolaridade } \\
\hline & Até $2 \mathrm{SM}$ & $\begin{array}{l}\text { Mais de } \\
2 \text { a } 5 \text { SM }\end{array}$ & $\begin{array}{c}\text { Mais de } \\
5 \text { a } 10 \mathrm{SM}\end{array}$ & $\begin{array}{c}\text { Mais de } \\
10 \text { a } 20 \text { SM }\end{array}$ & $\begin{array}{l}\text { Mais de } \\
20 \mathrm{SM}\end{array}$ & $\begin{array}{l}\text { Fundamental } \\
\text { Incompleto }\end{array}$ & $\begin{array}{c}\text { Fundamental } \\
\text { Completo }\end{array}$ & $\begin{array}{l}\text { Médio } \\
\text { Completo }\end{array}$ & $\begin{array}{l}\text { Ensino } \\
\text { Superior }\end{array}$ \\
\hline Votariam $(\%)$ & 50,6 & 50,7 & 51,6 & 56,6 & 64,2 & 48,5 & 51,6 & 62,6 & 69,5 \\
\hline Depende (\%) & 17,2 & 20,1 & 24,5 & 28,3 & 20,9 & 20,4 & 23,4 & 23,0 & 25,4 \\
\hline Não Votaria (\%) & 32,2 & 29,2 & 23,9 & 15,1 & 14,9 & 31,1 & 25,0 & 14,4 & 5,1 \\
\hline Números Absolutos (1) & 87 & 219 & 188 & 106 & 67 & 363 & 124 & 139 & 59 \\
\hline
\end{tabular}

Fonte: Pesquisa sobre Obrigatoriedade do Voto.

(1) Foram excluídos 15 entrevistados que não declararam opinião e 18 que não declararam a renda. 
Em alguns casos, as diferenças percentuais são bastante altas: $68,2 \%$ dos entrevistados com ensino fundamental incompleto nunca debatem sobre questões políticas. Esse índice cai para 13,6\% quando o entrevistado tem escolaridade universitária. O mesmo padrão se repete com o nível de renda: $67,7 \%$ dos entrevistados que recebem até dois salários mínimos nunca discutem política. Esse percentual cai para 29,9\% quando o nível de renda sobe para mais de 20 salários mínimos. O inverso também é observado: discute-se mais à medida que sobe o nível de renda e o tempo de escolaridade.

Um segundo fator observável na Tabela 3 é a generalizada desmotivação política que atinge uma ampla parcela dos entrevistados, independentemente de seu nível de renda e escolaridade. Verifica-se que mesmo entre os indivíduos de mais alta renda e escolaridade não prevalece o hábito de debater questões políticas nos círculos íntimos. Entre todos os segmentos observados, as taxas de desinteresse são bastante altas.

Portanto, os dados da pesquisa permitem afirmar que os fatores individuais exercem um peso crucial nos índices de participação política, atuando no sentido da segregação e da desigualdade, bem como que os índices de participação são, de um modo geral, baixos. Quanto aos fatores institucionais, é necessário analisar os problemas que estes enfrentam no Brasil.

Como Lijphart (1997) enfaticamente argumenta, os elementos institucionais, quando bem construídos, podem exercer um importante papel equalizador. Esse seria o caso do voto obrigatório (que será tratado adiante), do alistamento automático, do sistema eleitoral e partidário e de outras medidas menores, como planejar as eleições em datas favoráveis.
O alistamento automático é uma medida razoavelmente simples, que entrega ao Estado a responsabilidade de alistar, automaticamente, todos os cidadãos em idade de voto. ${ }^{10}$ Como é evidente, essa simplificação burocrática facilita a aproximação dos mais arredios, favorecendo o comparecimento eleitoral.

Segundo Lijphart, também os sistemas eleitoral e partidário podem contribuir para o comparecimento. Para o autor, o sistema eleitoral proporcional estimularia a participação, porque nesse sistema os grupos em minoria sabem que têm maiores chances de conquistar o seu percentual de cadeiras.

Outro fator destacável seria um sistema partidário forte e organizado, capaz de trazer à participação política vastos segmentos sociais desfavorecidos. Estudando a Venezuela, José Molina Vega (1989) mostra que "la partidización de la sociedad" tem sido um dos fatores importantes para o desenvolvimento do interesse político no país. Segundo o autor, trata-se de um movimento que se entranha pela sociedade civil, pois cerca de $26 \%$ dos eleitores venezuelanos são membros de algum partido.

No Brasil, a realidade é muito diversa. Segundo o IBGE (1998b), 20\% da população brasileira afirma simpatizar com algum partido político, mas apenas $3 \%$ são filiados. Em Londrina, foram encontrados percentuais semelhantes: $13,9 \%$ dos entrevistados afirmaram possuir preferência partidária, mas somente $2,9 \%$ participam das atividades do partido. O cruzamento de dados referente às atividades partidárias da população pesquisada traz informações interessantes.

Confirmando os dados da literatura política, verificase a existência de uma correlação positiva entre ter preferência partidária e ser politicamente motivado para as eleições. As informações apresentadas indicam que o par-

TABELA 3

Pessoas que Debatem sobre Questões Políticas, por Renda Familiar e Nível de Escolaridade, segundo Freqüência das Discussões Londrina - 1997

\begin{tabular}{|c|c|c|c|c|c|c|c|c|c|}
\hline \multirow[t]{2}{*}{ Freqüência } & \multicolumn{5}{|c|}{ Renda Familiar } & \multicolumn{4}{|c|}{ Nível de Escolaridade } \\
\hline & Até $2 \mathrm{SM}$ & $\begin{array}{l}\text { Mais de } \\
2 \text { a } 5 \text { SM }\end{array}$ & $\begin{array}{l}\text { Mais de } \\
5 \text { a } 10 \text { SM }\end{array}$ & $\begin{array}{c}\text { Mais de } \\
10 \text { a } 20 \text { SM }\end{array}$ & $\begin{array}{l}\text { Mais de } \\
20 \text { SM }\end{array}$ & $\begin{array}{l}\text { Fundamental } \\
\text { Incompleto }\end{array}$ & $\begin{array}{l}\text { Fundamental } \\
\text { Completo }\end{array}$ & $\begin{array}{l}\text { Médio } \\
\text { Completo }\end{array}$ & $\begin{array}{l}\text { Ensino } \\
\text { Superior }\end{array}$ \\
\hline Freqüentemente (\%) & 8,6 & 11,8 & 18,8 & 25,0 & 32,8 & 11,4 & 20,9 & 19,9 & 45,8 \\
\hline Às Vezes $(\%)$ & 23,7 & 24,0 & 32,5 & 35,2 & 37,3 & 20,4 & 31,8 & 44,7 & 40,7 \\
\hline Nunca $(\%)$ & 67,7 & 64,3 & 48,7 & 39,8 & 29,9 & 68,2 & 47,3 & 35,5 & 13,6 \\
\hline Números Absolutos (1) & 93 & 221 & 191 & 108 & 67 & 368 & 129 & 141 & 59 \\
\hline
\end{tabular}

Fonte: Pesquisa sobre Obrigatoriedade do Voto.

(1) Foram excluídos 18 entrevistados que não declararam a renda e três que não declararam opinião. 
tidarismo interfere, no sentido de levar à maior participação. Contudo, o percentual dos simpatizantes partidários constitui-se em pequena minoria da sociedade brasileira (bem como dos entrevistados em Londrina). Assim, o impacto positivo que porventura esse elemento institucional poderia provocar acaba sendo desprezível. Embora consociativo, o sistema eleitoral e partidário brasileiro apresenta uma fragilidade que dificulta o engajamento político da população.

Desta forma, pode-se afirmar que os índices de alienação eleitoral, verificados no Brasil, são altos em virtude de uma série de fatores individuais (como renda familiar e escolaridade) e institucionais (como a fragilidade dos partidos). Sendo assim, a solução do problema demandaria a adoção de medidas mais amplas nos dois campos, medidas capazes de transformar a própria estrutura da sociedade brasileira, juntamente com todas as suas mazelas. Evidentemente, este é um tema que extrapola os objetivos deste artigo, e não seria possível abordá-lo neste espaço. A pesquisa foi realizada com uma intenção mais simples e objetiva, qual seja, compreender o impacto da implantação do voto facultativo no Brasil.

\section{COMPULSORIEDADE E DEMOCRACIA}

Dentre as medidas institucionais que favorecem a participação eleitoral, o voto obrigatório tem sido considerado a mais importante. A percepção de que a compulsoriedade do voto realmente inibe a abstenção, garantindo uma presença maior nas eleições, baseia-se na observação de países que passaram por reformas na legislação e que, a partir daí, sofreram significativas mudanças nos índices de comparecimento (Irwin, 1974). Os surveys constituem outro tipo de pesquisa, comumente realizados nos países de voto obrigatório, com o objetivo de definir o perfil do eleitor motivado a participar se o voto fosse facultativo.

$\mathrm{Na}$ pesquisa realizada em Londrina, 52,6\% dos entrevistados afirmaram que votariam com certeza, caso o voto se tornasse facultativo; $21,4 \%$ responderam que talvez votassem, dependeria de alguns fatores; $23,9 \%$ não votariam com certeza e 2,1\% não souberam ou não quiseram responder. Estes índices são compatíveis com os percentuais nacionais ${ }^{11}$ e indicam que a implantação do voto facultativo acarretaria uma queda de $30 \%$ a $35 \%$ na participação da população brasileira nas eleições. Caso isso venha a ocorrer, o Brasil cairá para o nível dos países com os mais baixos percentuais de participação. ${ }^{12}$ Esta infor- mação leva à reflexão sobre as possíveis vantagens que a mudança para o voto facultativo traria para a democracia brasileira.

Dois argumentos têm pesado a favor da facultatividade do voto no Brasil. O primeiro, fundamentalmente próximo às idéias de Robert Dahl (1989), defende o voto facultativo para evitar que os cidadãos desinteressados da política participem sem nenhuma convicção: "obrigar a votar desvirtua o sentido da participação" (Serra, 1993: 28). Neste caso, a questão de fundo parece ser o envolvimento ideológico desses eleitores. São muitos os que acreditam que o voto dos mais politizados deve ser valorizado. Partilhando muitas vezes de ideologias de esquerda, defendem o direito de não comparecer como forma de limpar o processo eleitoral da interferência nefasta do clientelismo político e da coação dos "coronéis": "não podemos a pretexto de assegurar, naquelas regiões mais distantes do país, a presença do eleitor nas eleições, definir um mecanismo que contraria elementos básicos de um sistema democrático, que é voto como uma liberdade do cidadão, uma liberdade que deve ser assegurada mesmo em condições econômicas adversas como essa que vemos no Brasil, mesmo em uma situação de economia nacional em que, nas regiões mais distantes, campeia o curral eleitoral, a compra sistemática de votos, a corrupção e a fraude à vontade do eleitor. ${ }^{13}$

$\mathrm{O}$ segundo argumento, fundamentado em pesquisas de opinião, aponta que os mais interessados em política são também os indivíduos que desenvolvem mais coerentemente os ideais democráticos. Nesse sentido, a compulsoriedade seria responsável pela introdução, no cenário político, daqueles indivíduos menos tolerantes e menos conscientes que, espontaneamente, não participariam. Como argumenta Tulio Kahn (1997:187, nota 4), “é preciso lembrar no entanto que, ao menos no que se refere à

TABELA 4

Eleitores que Possuem e não Possuem Preferência Partidária, segundo Predisposição de Votar em Situação de Voto Facultativo Londrina - 1997

\begin{tabular}{lcc}
\hline Predisposição de Votar & $\begin{array}{c}\text { Têm Preferência } \\
\text { Partidária }\end{array}$ & $\begin{array}{c}\text { Não Têm Preferência } \\
\text { Partidária }\end{array}$ \\
\hline Votaria (\%) & 64,4 & 51,9 \\
Depende (\%) & 20,8 & 22,1 \\
Não Votariam (\%) & 14,9 & 26,0 \\
Números Absolutos (1) & 101 & 584 \\
\hline
\end{tabular}

Fonte: Pesquisa sobre Obrigatoriedade do Voto.

(1) Foram excluídos 15 entrevistados que não declararam opinião. 
participação eleitoral, certas regras institucionais do sistema brasileiro, como a obrigatoriedade do voto e a representação proporcional, por definição, jogam os intolerantes e não-democratas no cenário político, independentemente de seus interesses pelas atividades políticas".

Imagina-se, portanto, que a implantação do voto facultativo seria importante para trazer mudanças ao nível ideológico, seja no sentido de fortalecer os partidos progressistas e mais afinados com os interesses dos segmentos sociais, seja no sentido de fortalecer as idéias democráticas. Os dados da pesquisa de Londrina, entretanto, não confirmam essas hipóteses.

Embora a Tabela 5 sugira que, entre a esquerda ideológica, os índices de provável comparecimento seriam menores, essas diferenças percentuais não são estatisticamente significativas, e indicam que a implantação do voto facultativo não alteraria o caráter atual da representação política no Brasil. ${ }^{14}$

A Tabela 6 merece consideração mais detida. ${ }^{15}$ As diferenças entre democratas e autoritários não são estatisticamente significativas, indicando, portanto, que o comportamento dos dois grupos não diferiria se o voto fosse facultativo. A significância estatística deve-se aos que não sabem ou são indiferentes. Trata-se de um segmento que está alheio a estas questões. Realmente, seus valores não são democráticos, mas isto não significa que sejam autoritários.

Nos dois casos, não seria possível afirmar que a implantação do voto facultativo modificaria os resultados das eleições, elegendo candidatos mais democráticos ou mais à esquerda do espectro ideológico. Pelo contrário, os dados parecem indicar que não haveria mudanças consideráveis.

Esses dados de Londrina têm sido verificados em outras pesquisas de opinião. Como alertam Verba, Schlozman, Brady e Nie (1993), os surveys referentes à participação eleitoral costumam apresentar diferenças de cunho socio-

TABELA 5

Eleitores, por Ideologia Partidária, segundo Predisposição de Votar em Situação de Voto Facultativo Londrina - 1997

\begin{tabular}{lccc}
\hline Predisposição de Votar & Direita & Centro & Esquerda \\
\hline Votariam (\%) & 55,1 & 58,1 & 53,0 \\
Depende (\%) & 24,6 & 26,7 & 20,3 \\
Não Votariam (\%) & 20,3 & 15,1 & 26,6 \\
Números Absolutos (1) & 138 & 86 & 443 \\
\hline
\end{tabular}

Fonte: Pesquisa sobre Obrigatoriedade do Voto.

(1) Foram excluídos 33 entrevistados que não declararam opinião. lógico entre eleitores e não-eleitores, mas, no que diz respeito às opiniões políticas (como opinião sobre aborto, políticas de bem-estar e outras), não mostram diferenças significativas. Assim, as pessoas contrárias à obrigatoriedade poderiam desenvolver um terceiro argumento, que consistiria em afirmar que, não havendo diferenças nos resultados, os não-votantes estariam virtualmente representados, podendo ser liberados da obrigatoriedade sem perdas para a democracia.

Contrariando essa hipótese, Verba, Schlozman, Brady e Nie (1993) mostram em survey detalhado, no qual utilizam métodos mais precisos de medição, que, entre votantes e não-votantes, aparecem diferenças cruciais, que dizem respeito sobretudo a questões de políticas específicas. Sendo motivados principalmente pelas necessidades básicas, um percentual significativo dos não-votantes tem uma concepção diversa sobre as ações governamentais que consideram prioritárias. Segundo os autores, a abstenção eleitoral faz com que os segmentos socialmente desfavorecidos fiquem drasticamente sub-representados, pois suas necessidades econômicas e suas demandas com o governo são profundamente diversas das apresentadas pelos grupos mais participativos.

No Brasil, um estudo realizado com outras finalidades, mas que exemplifica com perfeição como essas divergências aparecem no plano concreto, é o livro de Maria D’Alva Kinzo (1988) sobre o MDB. Como a reconstituição da história do partido deixa claro, o crescimento eleitoral da oposição durante o regime militar deveu-se à combinação de duas políticas distintas, apoiadas por segmentos sociais diversos: de um lado, o projeto programático de construção do Estado de Direito; de outro, o atendimento imediato às demandas específicas. ${ }^{16}$

Verba, Nie e Kim (1987) afirmam que o voto compulsório é uma medida institucional que estabelece um piso

TABELA 6

Eleitores, por Valores Democráticos dos Candidatos em quem Votariam, segundo Predisposição de Votar em Situação de Voto Facultativo Londrina - 1997

\begin{tabular}{lccc}
\hline Predisposição de Votar & Democratas & Autoritários & $\begin{array}{c}\text { Não Sabem/ } \\
\text { Indiferentes }\end{array}$ \\
\hline Votariam (\%) & 56,4 & 52,5 & 30,8 \\
Depende (\%) & 21,2 & 23,2 & 26,9 \\
Não Votariam (\%) & 22,4 & 24,2 & 42,3 \\
Números Absolutos (1) & 532 & 99 & 52 \\
\hline
\end{tabular}

Fonte: Pesquisa sobre Obrigatoriedade do Voto.

(1) Foram excluídos 17 entrevistados que não declararam opinião. 
de participação política mínima para o cidadão. Lijphart (1997) retoma este argumento, mostrando que se trata de uma ação compensatória, pois, ao obrigar o comparecimento (não o voto, evidentemente), está-se garantindo que o maior número de cidadãos opinem sobre questões de seu interesse direto. Como já foi suficientemente frisado aqui, o objetivo desta regra é trazer para o espaço público cidadãos que espontaneamente não teriam motivações individuais para fazê-lo.

Os dados apresentados permitem supor que a situação brasileira é semelhante, apresentando alguns complicadores, tais como um sistema partidário e eleitoral mal construído e uma estrutura social extremamente desigualitária. Nesta perspectiva, é aconselhável que, além dos tradicionais argumentos a favor do voto obrigatório, se pondere também sobre esta questão. Acabar com a obrigatoriedade do voto seria retirar da legislação um dos poucos elementos equalizadores do sistema democrático brasileiro.

\section{NOTAS}

E-mail da autora: herrmann@sercomtel.com.br

Artigo apresentado no concurso para Professor Associado do Departamento de Ciências Sociais da Universidade Estadual de Londrina. A autora agradece aos professores Maria José de Rezende, Miguel Chaia e Pedro Roberto Ferreira, que participaram da banca examinadora e apresentaram sugestões que foram em grande parte incorporadas nesta versão final.

1. Em 1995, foi apresentado no Congresso Nacional o projeto de reforma política que inclui a implantação do voto facultativo. Ao final de 1998, após a reeleição do presidente Fernando Henrique Cardoso, líderes governistas e o próprio presidente declararam que a reforma deveria ser prioridade no segundo mandato. Recentes pesquisas de opinião igualmente indicam que a maioria da população apóia o fim da compulsoriedade: $58 \%$ da população brasileira é favorável ao voto facultativo, segundo dados do DataFolha (Folha de S.Paulo, 20/12/98); 68\% favorável, segundo dados de Londrina (Oliveira e Carvalho, 1998).

2. A reforma eleitoral na Venezuela não eliminou o caráter compulsório do voto, mas sim as penalidades para os não-votantes. Ver Molina Vega (1995).

3. A pesquisa sobre obrigatoriedade do voto foi desenvolvida em Londrina (PR), durante os meses de abril e maio de 1997, com 700 entrevistados, recebendo o apoio do CNPq e da Universidade Estadual de Londrina. Contou com a colaboração de Tiemi Matsuo, na parte estatística, dos alunos de Ciências Sociais, na pesquisa de campo, e a participação permanente de Marcolina N. Tomazini de Carvalho, no desenvolvimento do projeto.

4. Referem-se aos textos já clássicos de Lipset, 1967; Dahl, 1989; Verba, Nie e Kim, 1987.

5. Ver o dado sobre o Brasil em Lijphart (1997). A comparação com outras democracias está em Powell (1986).

6. Dados obtidos em IBGE, 1998b e TSE, 1998b.

7. Foi perguntado: "Em 1994, em quem votou para presidente da República? E para governador? E para senador? E para deputado federal? E para deputado estadual?"

8. Na pesquisa desenvolvida em Londrina, as variáveis sexo/idade/inserção no mercado de trabalho não foram significativas.

9. Foi perguntado: "Costuma discutir política com amigos e parentes?"

10. Veja uma análise sobre o alistamento automático na América Latina, em LeónRoesch (1992).
11. Com base em pesquisas nacionais realizadas pelo DataFolha, o jornal Folha de S.Paulo (13/09/98) apresentou os seguintes resultados: em 1989, 54\% dos eleitores votariam, mesmo com o voto facultativo; em 1994, esse percentual baixou para 49\%; em 1998, 50\% votariam.

12. Veja uma comparação em Powell (1986).

13. Depoimento do deputado federal Paulo Delgado (PT) para o Diário da Assembléia Nacional Constituinte, transcrito de Kahn (1992:80-81).

14. Foi perguntado: "Concorda que o governo deve cuidar apenas da segurança pública e da educação, deixando para os empresários os outros setores (saúde, habitação, estradas...)?" Buscava-se medir a convicção do entrevistado em relação ao tamanho do Estado (enxuto ou social-democrata). Sobre esta questão, ver Norberto Bobbio (1988).

15. Foi perguntado: "Na sua opinião, é importante para o país manter a liberdade democrática de voto, opinião e associação ou acha que, em determinadas situações, o governo não pode ser democrático?"

16. A entrevista com o ex-governador Orestes Quércia, transcrita no livro, ilustra bastante bem o conflito travado no interior do partido: "enquanto nos esforçamos para obter a restauração do habeas corpus, a revogação do Ato $\mathrm{n}^{\circ} 5$ e a defesa das liberdades democráticas, evidentemente cumprimos um dever primordial e nos dedicamos a causas justas e nobres. (...) Mas, também importante para o MDB é acompanhar a problemática nacional, as questões relacionadas com o desenvolvimento. (...) Afora a eleição direta, as franquias democráticas, há questões que interessam vitalmente à Nação e merecem a cogitação do povo. (...) Nossa tarefa é auscultar as aspirações do povo, interpretá-las e condensá-las num programa de ação imediata” (Kinzo, 1988:141).

\section{REFERÊNCIAS BIBLIOGRÁFICAS}

A OPINIÃO sobre as mudanças políticas. Folha de S.Paulo. São Paulo, Caderno I, 20/12/98, p. 13 .

ASSIS BRASIL, J.F. de. Democracia Representativa: do voto e do modo de votar 4ㄹ ed. Rio de Janeiro, Imprensa Nacional, 1931.

BOBBIO, N. Liberalismo e democracia. 2a ed. São Paulo, Pólis, 1988.

COM voto facultativo $50 \%$ não iriam às urnas. Folha de S.Paulo. São Paulo, Caderno Especial, 13/09/98, p.6.

DAHL, R. Um prefácio à teoria democrática. Rio de Janeiro, Zahar, 1989.

IBGE. Contagem da População - 1996 - Brasil. Censos. Rio de Janeiro, 1998a. Populações residentes - Município de Londrina (PR) - Ano 1991. Rio de Janeiro, 1998b.

IRWIN, G.A. "Compulsory voting legislation: impact on voter turnout in the Netherlands". Comparative Political Studies, v.7, n.3, October 1974, p.292315 .

LEÓN-ROESCH, M. "Los registros electorales en America Latina”. In: NOHLEN, D. (ed.). Elecciones y sistemas de partidos en América Latina. San Josél Costa Rica, IIDH, 1992, p.67-89.

KAHN, T. 0 voto obrigatório. Dissertação de Mestrado, São Paulo, Departamento de Ciência Política da Faculdade de Filosofia, Letras e Ciências Humanas da Universidade de São Paulo, 1992 p.175-197.

“Apatia política e credo democrático". Lua Nova, n.39, 1997,

KINZO, M.D. Oposição e autoritarismo: gênese trajetória do MDB (1966-1979). São Paulo, Vértice, 1988.

LIJPHART, A. "Unequal participation: democracy's unresolved dilemma". American Political Science Review, v.91, n.1, March 1997, p.1-14.

LIPSET, M. O homem político. Rio de Janeiro, Zahar, 1967.

MOLINA VEGA, J.H. "La participación electoral en Venezuela". Cuadernos de Capel. San José/Costa Rica, Capel, 1989.

"Los venezolanos abandonam el hábito de votar: la abstención en las elecciones de 1993". Boletin Electoral Latinoamericano, n.13, jan./jun. 1995, p.159-179.

NOHLEN, D. Sistemas electorales del mundo. Madri, Centro de Estudios Constitucionales, 1981.

OLIVEIRA, L.H.H. de e CARVALHO, M.N.T. de. "Divulgação de pesquisa: obrigatoriedade do voto e determinantes sociais". Revista Mediações, v.3, 
n.1, Programa de Pós-Graduação de Departamento de Ciências Sociais/UEL, 1998

POWELL, B.G. Jr. "American voter turnout in comparative perspective". American Political Science Review, v.80, n.1, March 1986, p.17-43.

SANTOS, W.G. dos. Crise e castigo: partidos e generais na política brasileira. São Paulo, Vértice, 1987, capítulo III.

SARTORI, G. A teoria da democracia revisitada. São Paulo, Ática, 1994.

SERRA, J. Reforma política no Brasil: parlamentarismo X presidencialismo, 3ed., São Paulo, Siciliano, 1993.

SOARES, G.A.D. Sociedade e política no Brasil. São Paulo, Difel, 1973.
TSE. Total de eleitores. Secretaria de Informática, 1998a (Estatísticas do Eleitorado de 1998).

Estatística dos eleitores de 1994. Sistema de Engenharia de Sistemas, 1998b.

VERBA, S.; NIE, N.H. e KIM, J. Participation and political equality (a sevennation comparison). USA, University of Chicago Press Edition, 1987.

VERBA, S.; SCHLOZMAN, K.U.; BRADY, H. e NIE, N.H. "Citizen activity: who participates? What do they say?" American Political Science Review, v.87, n.2, June 1993, p.303-318.

WOLFINGER, R. e ROSENSTONE, S.J. Who votes? New Haven and London, Yale University Press, 1980. 